\title{
Pediatric Malaria Incidence and Risk Mapping With and Without Clinical Data in Sussundenga Municipality, Mozambique
}

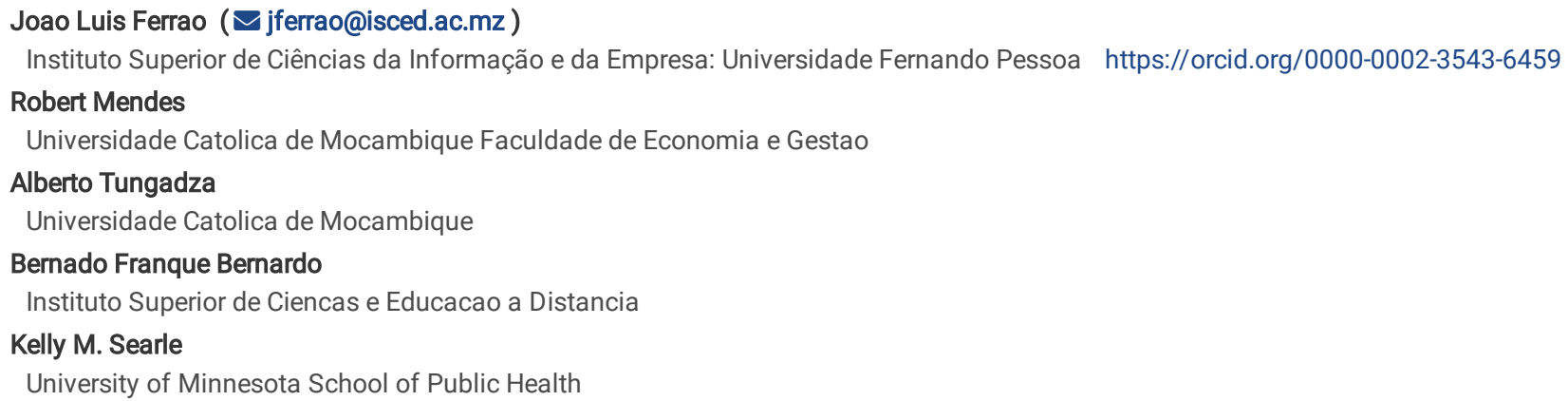




\section{Abstract}

Background

Malaria is a parasitic borne disease that affects red blood cells. The disease is preventable, detectable and treatable and more common in poor resource settings. It causes socioeconomic impacts, representing a large burden on the revenue of countries where it is endemic. Malaria is undoubtedly one of the main public health concerns impacting on families and the economy in Mozambique. Although the entire population of Mozambique is at risk of malaria, children and pregnant women have higher risk owing to lower immunity. Age category plays a significant important role in malaria occurrence and can affect the course and progression of the disease and correct treatment. Very few studies in pediatric malaria exists in Mozambique and the existing uses a simplistic and coarse grouping. Malaria risk is rarely uniform, whether considering households in a village, villages in a district or districts in a country. The knowledge of malaria pediatric incidence and, the need to evaluate the local heterogeneity by generating malaria risk maps can improve the understanding of pediatric malaria being the objective of this study.

Materials and Methods

A retrospective study was conducted using existing malaria positive data from 2018 to 2019 at Rural Sussundenga Hospital (RSH) in Sussundenga municipality. Attributable factor of the disease and incidence were calculated. Proportion of gender, age category and location were tested using $\mathrm{G}$ test. For malaria risk mapping, ten malaria factors (anthropic, sociodemographic, climatic and clinic) were used to produce two maps one using malaria incidence and other without. Bioclimatic, Diva GIS 7.4.0 and, Landsat 8 image were used to produce the map.

Results and conclusion

The findings revealed that of the, 42,248 patients who visited the local hospital f, $51.2 \%$ tested positive for malaria with an incidence of 45.7 per 100 persons. There is a difference between residential areas in malaria incidence, with both maps showing malaria risk in Nhamazara, Nhamarenza and Unidade communities. This implies that malaria high risk areas seem to be located in high populated areas and areas close to water bodies. Relevant information is provided for effective planning in malaria intervention.

\section{Introduction}

Malaria is a parasitic borne disease that affects red blood cells. World Health Organization recorded 229 million cases of malaria in 2019 and of these there were 409,000 deaths in 87 endemic countries and $67 \%$ in children under 5 years. Worldwide, $95 \%$ of the malaria cases occurred in 29 countries [1].

Mozambique is among the six countries accounting for half of all malaria cases and deaths in the world and it is on the 5th place. Worldwide, malaria prevalence and incidence decreased by 50 and $40 \%$ respectively due, to the control programs. In Southern Africa the malaria decrease was between 50 to 91 $\%$. In Mozambique the reduction is slow and, between 2015 and 2018, cases fall only by $14 \%$ [2, 3].

The disease is preventable, detectable and treatable and, more common in poor regions. It causes socioeconomic impacts, representing a large burden on the revenue of countries where it is endemic.

In Mozambique malaria is undoubtedly one of the main public health concerns impacting on families and the economy. In 2020 the country reported $8,921,081$ cases and 1,114 deaths [1]. Although the entire population of Mozambique is at malaria risk, children and pregnant women are at higher risk owing to lower immunity. in Chimoio region/province, in Mozambique children under five years old are three times more prone to malaria than adults [4].

Malaria transmission in Mozambique occur all year round, and the peak of malaria occurs between January to March. The malaria transmission has a strong association with rainfall, temperature with relative humidity accounting for 72 to $80 \%$ of the cases $[5,6,7]$.

Despite those weather conditions, malaria occurrence is also influenced by socio-demographic determinants such as age, gender, level of education, residence type (rural and urban) $[8,9,10]$. Age can affect the course and progression of the diseases and correct treatment [11]. Very few studies in pediatric malaria exists in Mozambique and the existing ones use simplistic and coarse grouping of 0 to 4 and over 5 years, not reflecting stages of development and the existing standard age categories.

The malaria environmental dependency result in a complex pattern of geographical variation in transmission at almost every scale. Malaria risk is rarely uniform whether considering between households in a village, villages in a district or districts in a country. The knowledge of spatial distribution of malaria and, the evaluation of local heterogeneity by generating malaria risk maps can improve the understanding of pediatric malaria especially in children.

Hence, the intention of this study is to determine the malaria determinants and mapping the risk of malaria in children with and without clinical data. The knowledge generated by the present study can help in the formulation of malaria control programs and policy strategies for malaria control in under 14 age categories in Mozambique.

\section{Material And Methods.}

a. Study area and population

Sussundenga village is a rural municipality in Manica Province, Mozambique administratively dived in 17 residential areas within an area of $156.9 \mathrm{Km}{ }^{2}$. (Figure 1). 
The population is 41,354 inhabitants, $52 \%$ females and $48 \%$ males with a $2.5 \%$ annual growth rate. The pediatric population (0 to 14 years) comprises 45.6 $\%$ of the total population being $4.4 \%$ less than 1 year, $11 \%$ from 1 to 4 years and, $30.2 \%$ from 5 to 14 years old [12]. The livelihood of the inhabitants is based on subsistence agriculture.

The hydrographic network comprises of 6 main rivers with permanent flow. In the municipality most of the population has deficient access to health services since there is only one public hospital.

The climate is warm temperate with dry winters from April to July, hot and dry summer from August to October and, hot humid summer from November to March. The average rainfall is $1,067.6 \mathrm{~mm}$, varying significantly in the amount and, distribution within and between October and November are the hottest month recording averages of $\left(30^{\circ} \mathrm{C}\right)$, July is coldest month with averages of $12^{\circ} \mathrm{C}$. The predominant vegetation, is associated with open, deciduous forests, evergreen forests, prairie, shrubs and savanna [13].

b. Data Collection and Analysis

In public hospitals all patients are registered in a record book at a visit. Malaria test at Sussundenga District Hospital (SDH) is carried out using rapid diagnostic test (RDT) and, few microscopic tests for confirmation. Patient daily data were collected from the book records of the Pediatric Department of SDH from November 2018 to October 2020 in 24 record books. For the positive malaria cases the following variable data were recorded: date, sex, origin and age category. The age was grouped into five age pediatric categories: 0 to 5,6 to 11,12 to 23,24 to 59 months and, 5 to 14 years old. Missing data were calculated and, since they were very low, $1.2 \%$, data with missing data were removed from the study.

The weight of the disease was calculated dividing the malaria positive cases by the total patient visits. The malaria incidence per 100 persons in each residential area was calculated by dividing the total number of cases occurring in each Bairro by the total population of the "Bairro" and then, multiplied by 100 [14]. Chi - Square and, G test test for proportion of gender and age category were used to test statistical significance.

For malaria risk mapping. Bioclimatic (WorldClim) [15], Diva GIS 7.4.0 [16], Landsat 8 image [17], accessed on September 29, 2019 with a resolution of $30 \mathrm{~m} x$ $30 \mathrm{~m}$ and, Digital Elevation Model (DEM) [18] of $30 \mathrm{~m} \times 30 \mathrm{~m}$ were used.

A three-step strategy was applied to develop the map namely: Step 1. Malaria risk factors identification, Step 2. Determining risk factor weights (Analytical Hierarchical Process and consistency check), Step 3, Mapping risk of malaria and accuracy assessment of the produced map

Step 1. Malaria risk factors identification

Ten risk factors used the weights, classes and rank are in table 1.

i) Population density (Inhabitants $/ \mathrm{Km}^{2}$ )

Density lower than 2,000 inhabitants per $\mathrm{Km}^{2}$ was considered has having a low risk, from 2,001 to 4,000 has having moderate risk while, over 4001 having high risk.

ii) Malaria Incidence per 100 persons per residential area

Incidence from 0 to 40 per 100 persons was considered low risk, 41 to 80 was considered moderate risk and, over 80 considered high risk.

iii) Altitude (meters)

Altitude lower than 200 meters was considered has having high malaria risk, from 201 to 1000 meters has having moderate malaria risk and, over 1000 meters has having a low malaria risk.

iv) average temperature $\left.\left({ }^{\circ} \mathrm{C}\right), \mathrm{v}\right)$ rainfall $(\mathrm{mm})$, vi) slope (degrees), vii NDVI (Index), viii) distance from the road (Km), ix) distance to waterbodies (Km) and, $\mathrm{x}$ ) land use and cover (LULC). For these variables, weights and classes were the same as descried by Ferrao et al [19].

Step 2. Determining risk factor weights (Analytical Hierarchical Process) and consistence check.

Analytical hierarchic process was determined as previous described [19]. To check for consistence, a true consistence ratio for the corresponding matrix was calculated by dividing the consistence index for the set of judgments by the index for the corresponding random matrix. Saaty suggests that if that ratio exceeds 0.1 , the set of judgments may be too inconsistent to be reliable [20].

Step 3. Mapping risk of malaria risk and accuracy check

Two risk maps were produced using spatial, anthropic, and environmental variables; one risk map using ten risk factors: while, the other excluded the incidence data. The mapping process was conducted as previously descried [19].

Tests were performed using SPSS IBM version 20 and for mapping ArcGIS 10.7.3 [21].

\section{Results}

a. Malaria incidence per age group in children 0 to 14 years old. 
From November 2018 to October 2020, 42,248 patients visited the pediatric department of SDH and 21,663 (51.2 \%) were positive to malaria. From the malaria positive patients $89.9 \%$ were from the Sussundenga municipality.

The incidence per 45.7 per 100 persons for year 2019 patients. As per gender, the malaria positive patients were $48.4 \%$ male and $51.6 \%$ females.

The average age of pediatric malaria patients was $5.7 \mathrm{SD}$ (Standard deviation) $=1.38$ years. Figure 2 presents age group distribution and, age group 0 to 5 month presented the least percentage of cases $3.3 \%$ while, the age group 5 to 14 years old presented the highest percentage of cases $45.6 \%$. No difference was found between sex among the age categories.

\section{b. Malaria incidence by residential areas}

The incidence per residential area varied from 6.6 per 100 persons to 118 per 100 persons. There is a difference between residential areas in malaria incidence $\mathrm{G}=377.38, \mathrm{P}=0.0001, \mathrm{DF}=16$ and, Nhamarenza present the highest incidence, 118 per 100 persons, and the least incidence was presented in residential areas Chizizira and Tave with 6.6 and 6.7 per 100 persons respectively (Figure 3).

c. Malaria cases by month

Figure 4 presents the percentage malaria pediatric cases for 2019 . January presented the highest percentage of cases $19.7 \%$ followed by May $19.6 \%$ and, the least percentage of cases occurred in September, $0.1 \%$.

d. Malaria risk mapping

\section{i. Analytical Hierarchical Process and consistency check}

Table 2 and 3 presents the comparison matrix of $10 \times 10$ and, $9 \times 9$ risk factors that were used. A value of 1 means that the malaria risk factors that are being compared have the same weight. A value of 4 for example a malaria risk factor in the column is four times more important in the malaria cases occurrence. The consistence ratio was 0.081 and 0.096 for $10 \times 10$ and $9 \times 9$ matrix respectively considered good enough.

\section{Mapping risk of malaria and accuracy check.}

Figure 5 presents the risk factor maps before reclassification. The average temperature in the area varies from 20.14 to $21.17{ }^{\circ} \mathrm{C}$, the rainfall from 1028 to $1,082.24 \mathrm{~mm}$, altitude from 459 to 791 meters, slope from 0 to $37.5^{\circ}$, distance to water bodies from 0 to 15,134 meters, NDVI from -0.14 to 0.5 , population density from 41 to 59,091 persons per $\mathrm{Km}^{2}$, malaria incidence from 2.9 to 118 persons per 100 and distance to roads from 0 to $13,510.7$ meters.

Figure 6 presents the maps for the reclassified risk factors and the malaria risk in percentage. Rainfall (100\%) and slope (73\%) has the highest risk, altitude $(100 \%)$ and NDVI (92\%) has the moderate risk in the municipality.

The spatial model derived to produce the two malaria risk maps from the risk factors are presented in formula 1 and 2.

Map $=($ Temperaturex 0.2259$)+($ Rainfallx 0.2001$)+($ altitudex 0.127$) x($ DTW Bx 0.0936$)+($ slopex 0.0828$)+($ LULC $x 0.0646)+($ po (1).

Map $=($ Temperaturex02183 $)+($ Rainfall $x 0.2105)+($ altitudex 0.1377$) x($ DTWBx0.0936 $)+($ slopex 0.10$)+($ LULCx 0.0935$)+($ pop (2).

Figure 7A and Figure 6B presents the final malaria risk maps for Sussundenga municipality after the consolidation and the weighting using the incidence data and, excluding the incidence data. The entire Sussundenga municipality his at risk of malaria varying from moderate to high risk. Malaria high risk seems to coincide with highly populated area and around waterbodies.

Table 4 presents the percentage of malaria risk in Sussundenga and there is now difference in the risk areas using and, excluding the clinical data (incidence data).

Table 4A and $\mathrm{B}$ presents the area of the high and moderate malaria risks

\section{A. Including Incidence B. Excluding Incidence.}

In this study the pediatric malaria weight of malaria was $51.2 \%$. In 2015 malaria was responsible for $45 \%$ of outpatient visits and $56 \%$ of pediatric admissions in Mozambique [2] consistency with these results. A study in Manhiça, a rural area in the south of Mozambique in 2008 [22] indicated $30.5 \%$ had malaria, lower than the results of the present study and, this can be related to environmental conditions since the south of Mozambique is more arid. In Malawi a neighboring country the weight of de disease ranged from $26 \%$ in Salima to $64 \%$ in Mwanza [23].

The malaria incidence in pediatric malaria in this study was 45.7 per 100 persons. A 2018 study reported an incidence of 39 per 100 in children under 10 years in the Central region of Mozambique [24]. A study in Malawi indicated 35 to 37 per 100-person incidence in children under 15 in 2017 [9]. In Zimbabwe significant progress was made in malaria cases reduction and the incidence is of 2.5 per 100 persons while, in Zambia is of 20 per 100 persons [25,26].

The mean age of malaria patients in this study was 5.6 SD 1.3 years. In Southern Africa a review of 29 studies in 2010 reported a median age of clinical malaria of 32 month highly intense and not markedly seasonal transmission areas and 72 months in settings of low intensity and markedly seasonal 
transmission area consistent to this study [27]. In China the mean average of most childhood diseases was reported to range from 20 to 80 months and, for high incidence pediatric disease approximately 3 years [28].

In this study, the age group 5 to 14 years old presented the highest percentage of cases $45.6 \%$ while this category comprises $30.2 \%$ of the municipality inhabitants. A community study in the same municipality in 2021 reported $50 \%$ of positive cases of malaria in children aged 5 to 14 years [29] consistent with these results. A study in Manhiça Mozambique [22] reported $36 \%$ of cases among age group 5 to 14 in 2008 less than in this study and, while, a study in Inhambane, Mozambique [30] in 2015, reported higher figure of $67.7 \%$. In Malawi and Kenya results consistent with the present findings were reported [31,32]

A shift in the peak age of cases from $1-4$ years old to 5 to 9 years old was reported in 2009 in a study in Inhambane, Mozambique [30]. In many malariaendemic areas, successful control programs have reduced the level of transmission substantially and consequently, in such communities, the peak age of clinical attacks of malaria is shifting from very young to older children $[33,34,35]$.

The least malaria cases in this study occurred in children aged 0 to 5 months. For approximately six months after birth, antibodies acquired from the mother during pregnancy protect the child. This maternal immunity is gradually lost as the child begins to develop his or her own immunity to malaria. In areas where malaria is endemic, children are believed to achieve a high level of immunity up to 5 years of age [36,37]. Higher usage of bed nets was also reported in pregnant mothers and children less than one year than in children 5 to 14 years [30,36].

In this study, there was a difference in malaria incidence between residential areas varying from 6.6 to 118 per 100 persons. The results are consistent with studies in Chimoio, Sussundenga and, in Mozambique [4, 6, 29, 37, 38]. In Ethiopia and Kenya spatial variation of malaria incidence in a geographically homogeneous area was also reported $[39,40\}$ and, this can be a result of high endemicity. Heterogeneous rates from 2.5 to 10.5 episodes per 100 children year was also reported in Senegal [41]. In Malawi, geographical groups of households where children experienced repeated malaria infections overlapped with high mosquito's density areas [42]. In Brazil, the high incidence of malaria at low scale was due to the heavily modified landscape [43].

Most malaria cases occur from January to March in Mozambique [5, 6]. For 2019 the high malaria cases prolonged from January to May. This is a result of the Cyclone IDAl that occurred in March 2019 that resulted in heavy rain and floods in the region. The malaria temporality was also reported in other countries in Africa [45].

\section{Conclusion}

Age of pediatric malaria is shifting from 0 to 4 to age category 5 to 14 years and, targeting this category in efforts to combat malaria should be addressed. Mapping malaria risk at low scale is feasible without the use of clinical data and, can provide tools to improve the strategy of malaria combat in children. The malaria eradication needs to involve not only medical disciplines but also other fields such as economics, geography and ecology and, social sciences. The use of GIS and mapping can, contribute for the design and implementation of control malaria strategies by defining precisely the pattern of malaria occurrence.

\section{Declarations}

\section{Ethics of approval and consent to participate}

This study is part of the Malaria Risk, Prevention, and Health Seeking Behaviors in Sussundenga, Mozambique Project. All participants, or the guardians provided informed written assent and consent prior to participation. Ethical review and approval for the study was completed by the Institutional Review Board (IRB) at the University of Minnesota [STUDY00007184] and from A Comissão Nacional de Bioética em Saúde (CNBS) at the Ministry of Health of Mozambique [IRB00002657].

\section{Consent for publication}

N/A

\section{Availability of data and materials}

Data are available as additional file 1.

\section{Competing interests Competing}

The authors declare that that have no any competing interests

\section{Funding}

This study was funded through a SEED grant from the University of Minnesota Center for Global Health and Social Responsibility (CGHSR). They provided funds to carry out the study.

\section{Author's contributions}

JLF contributed in supervising the data collection process, writing the manuscript and statistical analysis, RM contributed in Mapping, AT and BFB contributed in data collection and, KMS, oversaw the analyses and critical review, of the manuscript. All authors have read and, approved the manuscript. 


\section{Acknowledgments}

We would like to thank the Provincial and district directorates of health to grant permission to carry out this study specially the Dr. Firmino Jaqueta, Dr. Serafina Benesse, Dr. Filipe Murgorgo and Mrs. Elsa Trabuco. To Mrs Jesca Mutowo for the English revision.

\section{References}

1. World Health Organization. World malaria report 2020: 20 years of global progress and challenges. Geneva: WHO; 2020.

https://www.who.int/teams/global-malaria-programme/reports/world-malaria-report-2020. Accessed on 10/8/2021

2. Mozambique malaria facts. Severe Malaria Observatory. https://www.severemalaria.org/severe-malaria-resources.(Accessed on 10/8/2020)

3. O'Meara WP, Mangen JN, Steketee R, Greenwood B. Changes in the burden of malaria in sub-Saharan Africa. Lancet Infect Dis 2010; 10: 545-55. DOI:10.1016/S1473-3099(10)70096-7. .(Accessed on 10/8/2020)

4. Ferrão, J.L., Mendes, J.M., Painho, M. et al. Spatio-temporal variation and socio-demographic characters of malaria in Chimoio municipality, Mozambique. Malar J 15, 329 (2016). https://doi.org/10.1186/s12936-016-1371. (Accessed on 11/8/2020.

5. Ferrão JL, Mendes JM, Painho M. Modelling the influence of climate on malaria occurrence in Chimoio Municipality, Mozambique. Parasit Vectors. 2017 May 25;10(1):260. doi: 10.1186/s13071-017-2205-6. .(Accessed on 10/8/2020)

6. Zacarias OP. Anderson M. Spatial and temporal patterns of malaria incidence in Mozambique. Malar J 2011 10:189. doi: 10.1186/1475-2875-10-189. https://pubmed.ncbi.nlm.nih.gov/21752284/. .(Accessed on 10/8/2020)

7. Arroz JA. Increase in cases of malaria in Mozambique, 2014: epidemic or new endemic pattern?.. Rev Saude Publica. 2016;50:5. doi:10.1590/S15188787.2016050006105. .(Accessed on 10/8/2020)

8. Sultana M, Sheikh N, Mahumud RA, Jahir T, Islam Z, Sarker AR. Prevalence and associated determinants of malaria parasites among Kenyan children. Trop Med Health. 2017 Oct 23;45:25. doi: 10.1186/s41182-017-0066-5. (Accessed on 8/3/2021).

9. Chilanga, E., Collin-Vézina, D., Maclntosh, H. et al. Prevalence and determinants of malaria infection among children of local farmers in Central Malawi. Malar J 19, 308 (2020). https://doi.org/10.1186/s12936-020-03382-7. .(Accessed on 10/8/2020)

10. Carlucci, J.G., Blevins Peratikos, M., Cherry, C.B. et al. Prevalence and determinants of malaria among children in Zambézia Province, Mozambique. Malar J 16, 108 (2017). https://doi.org/10.1186/s12936-017-1741-z. (Accessed on 10/8/2020)

11. Geifman N, Cohen R, Rubin E. Redefining meaningful age groups in the context of disease. Age (Dordr). 2013;35(6):2357-2366. doi:10.1007/s11357-0139510-6. .(Accessed on 10/8/2020)

12. Instituto Nacional de Estatística. Estatísticas Distritais (Estatísticas do Distrito de Sussundenga). Available online: http://www.ine.gov.mz/estatisticas/estatisticas-territorias-distritais/manica/2011/distrito-de-sussundenga.pdf/view, (Accessed on 10 July 2020).

13. Clima Sussundenga. https://www.worldweatheronline.com/sussundenga-weather-averages/manica/mz.aspx. Available online. .(Accessed on 10/8/2020)

14. Principles of Epidemiology in Public Health Practice. Centre for Disease Control. 2011. Third Edition. https://www.cdc.gov/csels/dsepd/ss1978/index.html, accessed on 10 July 2020.

15. BIOCLIM: WorldClim Bioclimatic Variables $(2000,20,50,80)$. Available online: https://www.edenextdata.com/?q=content/bioclim-worldclim-bioclimaticvariables-2000-20-50-80 (accessed on10/10/2020).

16. DIVA-GIS. Available online: https://www.gbif.org/tool/81420/diva-gis (accessed on 15/10/2020).

17. Lansat 8. Landsat-8 Imagery in the Period 2019. Available online: https://eoportal.org/web/eoportal/satellite-missions/l/landsat-8-2019 (accessed on 15/10/2020).

18. Digital Elevation Models (DEMs). Available online: https://www.usgs.gov/faqs/what-are-digital-elevation-models-dems?qt-news_science_products=0\#qtnews_science_products (accessed on 15/10/2020).

19. Ferrao JL, Niquisse S, Mendes JM, Painho M. Mapping and Modelling Malaria Risk Areas Using Climate, Socio-Demographic and Clinical Variables in Chimoio, Mozambique. IJERPH. 218. 15. https://www.mdpi.com/1660-4601/15/4/795

20. Coyle G. The Analytical Hierarchical Process. 2004. https://training.fws.gov/courses/references/tutorials/geospatial/CSP7306/Readings/AHPTechnique.pdf. (Accessed on 10/11/2020).

21. ArcGIS Desktop 10.7.1 Quick Start Guide. Available online: https://desktop.arcgis.com/en/arcmap/10.7/get-started/setup/arcgis-desktop-quick-startguide.htm (accessed on 10/10/2020).

22. Guinovart, C., Bassat, Q., Sigaúque, B.et al.Malaria in rural Mozambique. Part I: Children attending the outpatient clinic. Malar J 7, 36 (2008). https://doi.org/10.1186/1475-2875-7-36

23. Okiro EA, Kazembe LN, Kabaria CW, Ligomeka J, Noor AM, Ali D, et al. (2013) Childhood Malaria Admission Rates to Four Hospitals in Malawi between 2000 and 2010. PLoS ONE 8(4): e62214. https://doi.org/10.1371/journal.pone.0062214

24. Mabunda, S., Casimiro, S., Quinto, L. et al. A country-wide malaria survey in Mozambique. I. Plasmodium falciparum infection in children in different epidemiological settings. Malar J 7, 216 (2008). https://doi.org/10.1186/1475-2875-7-216.

25. Sande, S., Zimba, M., Mberikunashe, J. et al. Progress towards malaria elimination in Zimbabwe with special reference to the period 2003-2015. Malar J16, 295 (2017). https://doi.org/10.1186/s12936-017-1939-0

26. Severe Malaria Observatory. Malaria in Zâmbia. https://www.severemalaria.org/countries/zambia. 
27. Carneiro I, Roca-Feltrer A, Griffin JT, Smith L, Tanner M, et al. (2010) Age-Patterns of Malaria Vary with Severity, Transmission Intensity and Seasonality in Sub-Saharan Africa: A Systematic Review and Pooled Analysis. PLoS ONE 5(2): e8988. doi: 10.1371/journal.pone.000898

28. Li, H., Yu, G., Dong, C. et al. PedMap: a pediatric diseases map generated from clinical big data from Hangzhou, China. Sci Rep9, 17867 (2019). https://doi.org/10.1038/s41598-019-54439-

29. Ferrao JL, Earland D, Nvela A, Mendes R, Ballat M, Tungadza A, Bibe A, Searle K. Modelling Sociodemographic factors that affects Malaria prevalence in Sussundenga Mozambique. Researchsquare. 2020. https://www.researchsquare.com/article/rs-614728/v1

30. Charlwood JD, Tomás EV, Bragança M, Cuamba N, Alifrangis M, Stanton M. Malaria prevalence and incidence in an isolated, meso-endemic area of Mozambique. PeerJ. 2015;3:e1370. Published 2015 Nov 5. doi:10.7717/peerj.1370

31. Walldorf JA, Cohee LM, Coalson JE, et al. School-Age Children Are a Reservoir of Malaria Infection in Malawi. PLoS One. 2015;10(7): e0134061. Published 2015 Jul 24. doi: 10.1371/journal.pone.0134061

32. Khagayi, S., Desai, M., Amek, N. et al. Modelling the relationship between malaria prevalence as a measure of transmission and mortality across age groups. Malar J 18, 247 (2019). https://doi.org/10.1186/s12936-019-2869-9

33. Pemberton-Ross, P., Smith, T.A., Hodel, E.M. et al. Age-shifting in malaria incidence as a result of induced immunological deficit: a simulation study. Malar J 14, 287 (2015). https://doi.org/10.1186/s12936-015-0805-1

34. Touré, M., Sanogo, D., Dembele, S. et al. Seasonality and shift in age-specific malaria prevalence and incidence in Binko and Carrière villages close to the lake in Selingué, Mali. Malar J 15, 219 (2016). https://doi.org/10.1186/s12936-016-1251-4

35. Griffin, J., Ferguson, N. \& Ghani, A. Estimates of the changing age-burden of Plasmodium falciparummalaria disease in sub-Saharan Africa. Nat Commun 5, 3136 (2014). https://doi.org/10.1038/ncomms4136

36. White M, Watson J. Malaria: Age, exposure and immunity. eLife 2018;7: DOI: 7554/eLife.4015. https://elifesciences.org/articles/40150

37. World Bank. Inquérito Nacional sobe indicadores de Malaria 2018. World Bank. 2019. https://microdata.worldbank.org/index.php/catalog/3488 (Acessed on 8/8/2021).

38. Geostatistical analysis and mapping of malaria risk in children of Mozambique Bedilu Alamirie EjigulD* Department of Statistics, College of Natural and Computational Sciences, Addis Ababa University, Addis Ababa, Ethiopia * alamirie@aau.edu.

39. Bejon P, Williams TN, Nyundo C, Hay SI, Benz D, Gething PW, et al. A micro-epidemiological analysis of febrile malaria in Coastal Kenya showing hotspots within hotspots. Elife. 2014;3, e02130

40. Nophar Geifman \& Raphael Cohen \& Eitan RubinRedefining meaningful age groups in the context of diseases. AGE (2013) 35:2357-2366 DOI 10.1007/s11357-013-9510-6

41. Espié E, Diene Sarr F, Diop F, et al. Spatio-Temporal Variations in Malaria Incidence in Children Less than 10 Years Old, Health District of Sokone, Senegal, 2010-2013. PLoS One. 2015;10(9):e0137737. Published 2015 Sep 18. doi: 10.1371/journal.pone.0137737.

42. Kabaghe, A.N., Chipeta, M.G., Gowelo, S. et al. Fine-scale spatial and temporal variation of clinical malaria incidence and associated factors in children in rural Malawi: a longitudinal study. Parasites Vectors 11, 129 (2018). https://doi.org/10.1186/s13071-018-2730-

43. de Oliveira Padilha, M.A., de Oliveira Melo, J., Romano, G. et al. Comparison of malaria incidence rates and socioeconomic-environmental factors between the states of Acre and Rondônia: a spatio-temporal modelling study. Malar J 18, 306 (2019). https://doi.org/10.1186/s12936-019-2938-0

44. Dalrymple, U., Mappin, B. \& Gething, P.W. Malaria mapping: understanding the global endemicity of falciparum and vivax malaria. BMC Med 13,140 (2015). https://doi.org/10.1186/s12916-015-0372-x

45. Spatio-Temporal Variations in Malaria Incidence in Children Less than 10 Years Old, Health District of Sokone, Senegal, 2010-2013 Emmanuelle Espié1 *, Fatoumata Diene Sarr1 , Fodé Diop2,3, Joseph Faye1 , Vincent Richard1 , Adama Tall1 , Aissatou Touré Baldé2

\section{Tables}

Table 1. Malaria risk factor, weights and classes of anthropic and environmental conditions. 


\begin{tabular}{|c|c|c|c|}
\hline Risk Factor & Weight \% & Class & Rank \\
\hline \multirow[t]{3}{*}{ Average Temperature oC } & 22.4 & $22-32$ & 3 \\
\hline & & $>32$ & 2 \\
\hline & & $<22$ & 1 \\
\hline \multirow[t]{3}{*}{ Precipitation (mm) } & 20.8 & $>700$ & 3 \\
\hline & & $450-700$ & 2 \\
\hline & & $<450$ & 1 \\
\hline \multirow[t]{3}{*}{ Altitude (mm) } & 10.4 & $<200$ & 3 \\
\hline & & $201-1000$ & 2 \\
\hline & & $>1001$ & 1 \\
\hline \multirow[t]{3}{*}{ Slope (degrees) } & 7.3 & $0-5$ & 3 \\
\hline & & $5-15$ & 2 \\
\hline & & $>15$ & 1 \\
\hline \multirow[t]{3}{*}{ LULC } & 8.2 & Agric. crop area, grass and water body. & 3 \\
\hline & & Shrubland \& mosaic cover vegetation & 2 \\
\hline & & Forest, bare and urban settlement & 1 \\
\hline \multirow[t]{3}{*}{ DTWB (Km) } & & $<500$ & 3 \\
\hline & & $500-1500$ & 2 \\
\hline & & $>1500$ & 1 \\
\hline \multirow[t]{3}{*}{ DTR (Km) } & 3.8 & $>5$ & 3 \\
\hline & & $2.5-5$ & 2 \\
\hline & & $<2.5$ & 1 \\
\hline \multirow[t]{3}{*}{ Population Density } & 5.1 & $>4001$ & 3 \\
\hline & & $2001-4000$ & 2 \\
\hline & & $<2000$ & 1 \\
\hline \multirow[t]{3}{*}{ Incidence per 100 persons } & 5.1 & 0 to 40 & 3 \\
\hline & & $41-80$ & 2 \\
\hline & & $<81$ & 1 \\
\hline \multirow[t]{3}{*}{ NDVI } & 4.7 & $0.255-0.986$ & 3 \\
\hline & & $0-0.25$ & 2 \\
\hline & & $-0.288-\quad 0$ & 1 \\
\hline
\end{tabular}

Source: Adapted from: Ferrao et al. Mapping and Modelling Malaria Risk Areas Using Climate, Socio-Demographic and Clinical Variables in Chimoio, Mozambique.

Table 2. $10 \times 10$ risk factors comparison matrix 


\begin{tabular}{|l|l|l|l|l|l|l|l|l|l|l|}
\hline Risk Factor & Temp. ${ }^{\circ C}$ & Rainfall mm & Alt.m & Slope ${ }^{\circ}$ & LULC & $\begin{array}{l}\text { DTWB } \\
\text { Km }\end{array}$ & $\begin{array}{l}\text { DTR } \\
\text { Km }\end{array}$ & $\begin{array}{l}\text { Pop dens } \\
\text { hab/Km }\end{array}$ & Incidence & NDVI \\
\hline Temp. $\left.{ }^{(\circ} \mathrm{C}\right)$ & 1,00 & 1,00 & 3,00 & 4,00 & 4,00 & 2,00 & 7,00 & 4,00 & 4,00 & 5,00 \\
\hline Randall (mm) & 1,00 & 1,00 & 3,00 & 4,00 & 3,00 & 1,00 & 7,00 & 4,00 & 4,00 & 3,00 \\
\hline Alt.(m) & 0,33 & 0,33 & 1,00 & 3,00 & 3,00 & 1,00 & 4,00 & 2,00 & 2,00 & 3,00 \\
\hline Slope( $\left.{ }^{\circ}\right)$ & 0,25 & 0,25 & 0,33 & 1,00 & 1,00 & 2,00 & 1,00 & 3,00 & 2,00 & 2,00 \\
\hline LULC & 0,25 & 0,33 & 0,33 & 1,00 & 1,00 & 2,00 & 2,00 & 3,00 & 1,00 & 1,00 \\
\hline DTWB( Km) & 0,50 & 1,00 & 1,00 & 0,50 & 0,50 & 1,00 & 2,00 & 3,00 & 3,00 & 2,00 \\
\hline DTR (Km) & 0,14 & 0,14 & 0,25 & 1,00 & 0,50 & 0,50 & 1,00 & 1,00 & 1,00 & 2,00 \\
\hline $\begin{array}{l}\text { Pop Dens } \\
\left.\text { (hab/Km }{ }^{2}\right)\end{array}$ & 0,25 & 0,25 & 0,50 & 0,33 & 0,33 & 0,33 & 1,00 & 1,00 & 2,00 & 4,00 \\
\hline Incidence & 0,25 & 0,25 & 0,50 & 0,50 & 1,00 & 0,33 & 1,00 & 0,50 & 1,00 & 2,00 \\
\hline NDVI & 0,20 & 0,33 & 0,33 & 0,50 & 1,00 & 0,50 & 0,50 & 0,25 & 0,50 & 1,00 \\
\hline
\end{tabular}

Temp $=$ Average temperature, Alt $=$ Altitude, LULC $=$ Land Use and Land cover, DTWB = Distance to waterbodies, DTR = distance to road, Pop dens = population density, NDVI - Norma difference index.

Table 3. $9 \times 9$ risk factors comparison matrix

\begin{tabular}{|c|c|c|c|c|c|c|c|c|c|}
\hline Risk Factor & Temp. ${ }^{\circ C}$ & Rainfall mm & Alt.m & Slope ${ }^{\circ}$ & LULC & DTWB Km & DTR Km & $\begin{array}{l}\text { Pop dens } \\
\text { hab/ } / \mathrm{Km}^{2}\end{array}$ & NDVI \\
\hline Temp. $\left.{ }^{(0} \mathrm{C}\right)$ & 1,00 & 1,00 & 3,00 & 4,00 & 3,00 & 2,00 & 7,00 & 4,00 & 3,00 \\
\hline Ranfall (mm) & 1,00 & 1,00 & 3,00 & 4,00 & 3,00 & 1,00 & 7,00 & 4,00 & 3,00 \\
\hline Alt.(m) & 0,33 & 0,33 & 1,00 & 3,00 & 3,00 & 1,00 & 4,00 & 2,00 & 3,00 \\
\hline Slope $\left({ }^{\circ}\right)$ & 0,25 & 0,25 & 0,33 & 1,00 & 1,00 & 2,00 & 3,00 & 3,00 & 2,00 \\
\hline LULC & 0,33 & 0,33 & 0,33 & 1,00 & 1,00 & 2,00 & 3,00 & 3,00 & 1,00 \\
\hline DTWB( Km) & 0,50 & 1,00 & 1,00 & 0,50 & 0,50 & 1,00 & 3,00 & 3,00 & 2,00 \\
\hline DTR $(\mathrm{Km})$ & 0,14 & 0,14 & 0,25 & 0,33 & 0,33 & 0,33 & 1,00 & 1,00 & 2,00 \\
\hline $\begin{array}{l}\begin{array}{l}\text { Pop Dens } \\
\left(\mathrm{hab} / \mathrm{Km}^{2} \text { ) }\right.\end{array} \\
\end{array}$ & 0,25 & 0,25 & 0,50 & 0,33 & 0,33 & 0,33 & 1,00 & 1,00 & 4,00 \\
\hline NDVI & 0,33 & 0,33 & 0,33 & 0,50 & 1,00 & 0,50 & 0,50 & 0,25 & 1,00 \\
\hline
\end{tabular}

Temp $=$ Average temperature, Alt $=$ Altitude, LULC $=$ Land Use and Land cover, DTWB $=$ Distance to

waterbodies, DTR = distance to road, Pop dens = population density, NDVI - Norma difference index .

Table 4. Percentage of malaria risk area in Sussundenga Municipality

A.

A

\begin{tabular}{|c|c|c|}
\hline Risk of Malaria & $\begin{array}{c}\text { Area } \\
\text { (hectares) }\end{array}$ & $\%$ \\
\hline 2 (Moderate) & $16,333,11$ & 99,72 \\
\hline 1 (High) & 46,44 & 0.28 \\
\hline
\end{tabular}

B

\begin{tabular}{|c|c|c|}
\hline Risk of Malaria & $\begin{array}{c}\text { Area } \\
\text { (hectares) }\end{array}$ & $\%$ \\
\hline 2 (Moderate) & $16,332,66$ & 99.7 \\
\hline 1 (High) & 46,89 & 0.3 \\
\hline
\end{tabular}

\section{Figures}




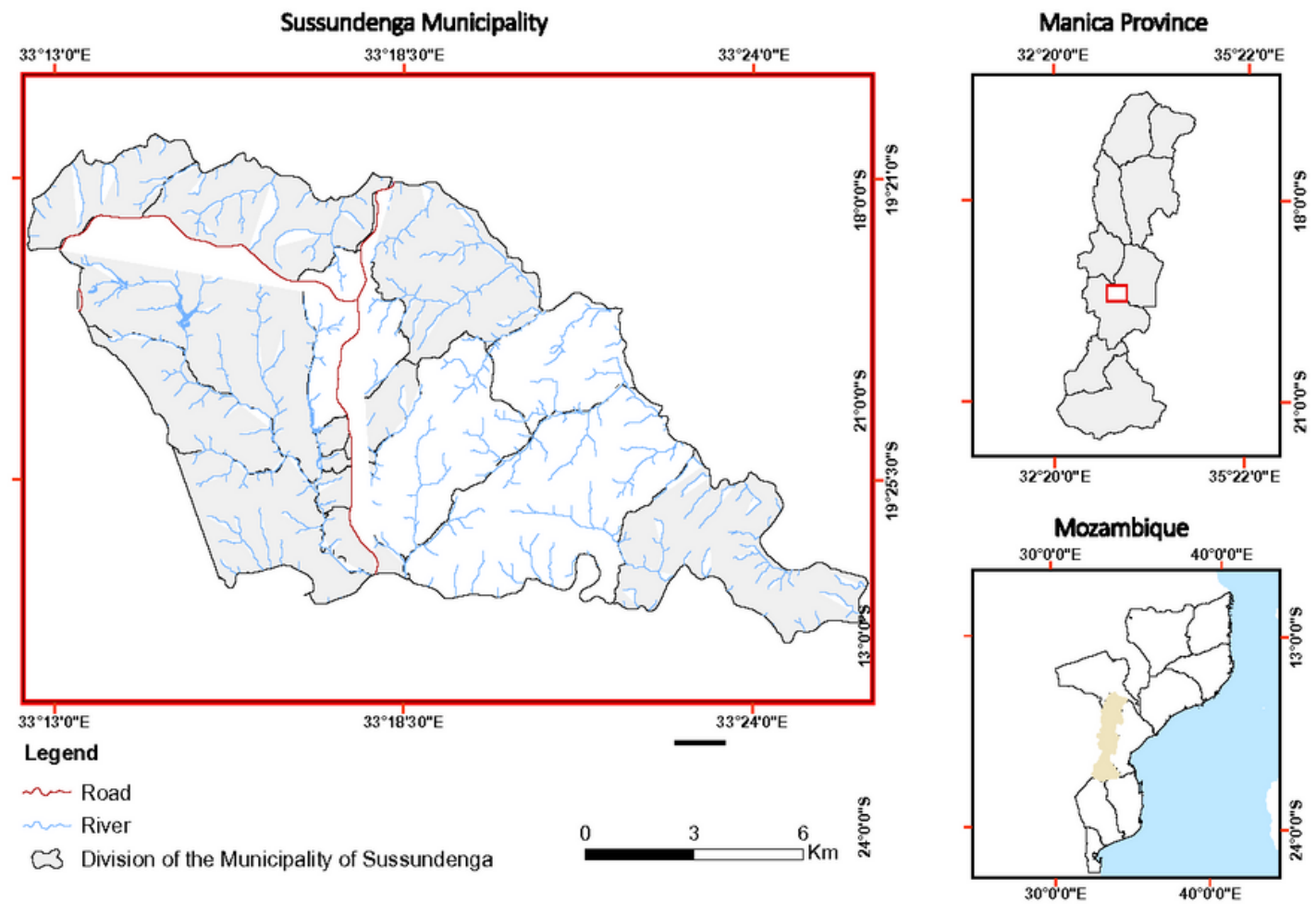

Figure 1

Study area, Sussundenga Municipality 


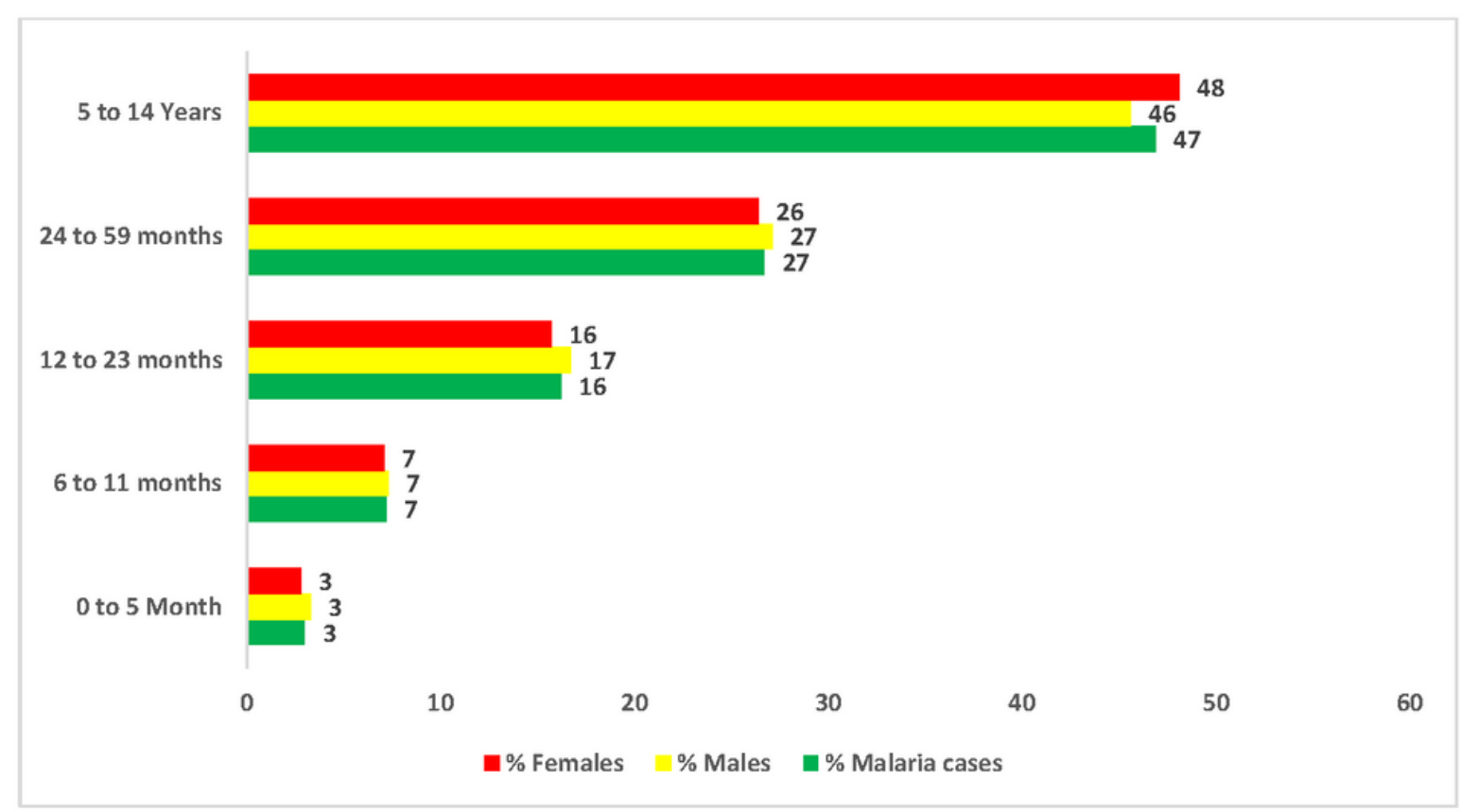

\section{Figure 2}

Percentage of malaria cases by age category and sex in Sussundenga incidence. 


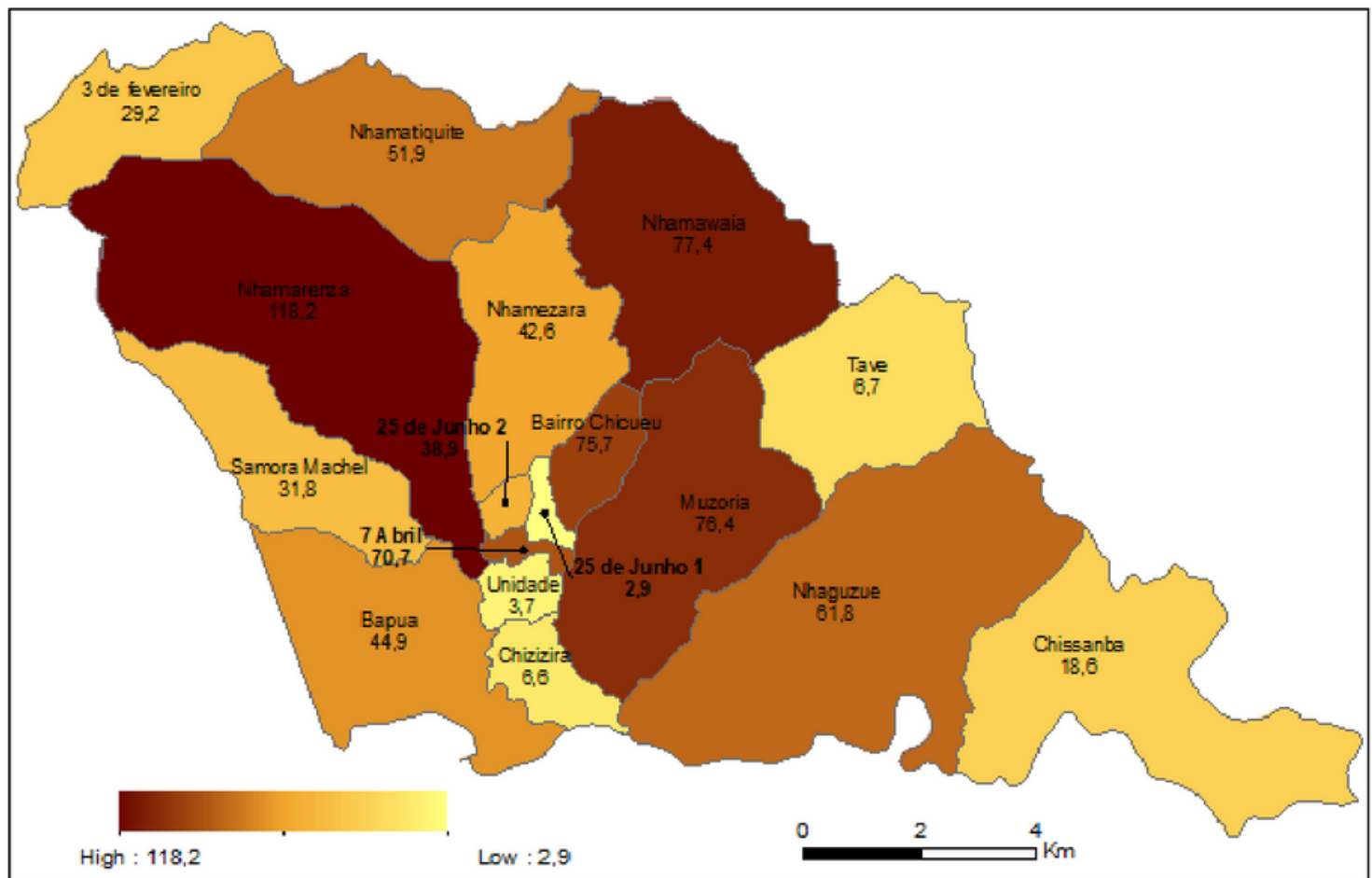

Figure 3

Malaria incidence per residential area in Sussundenga Municipality 


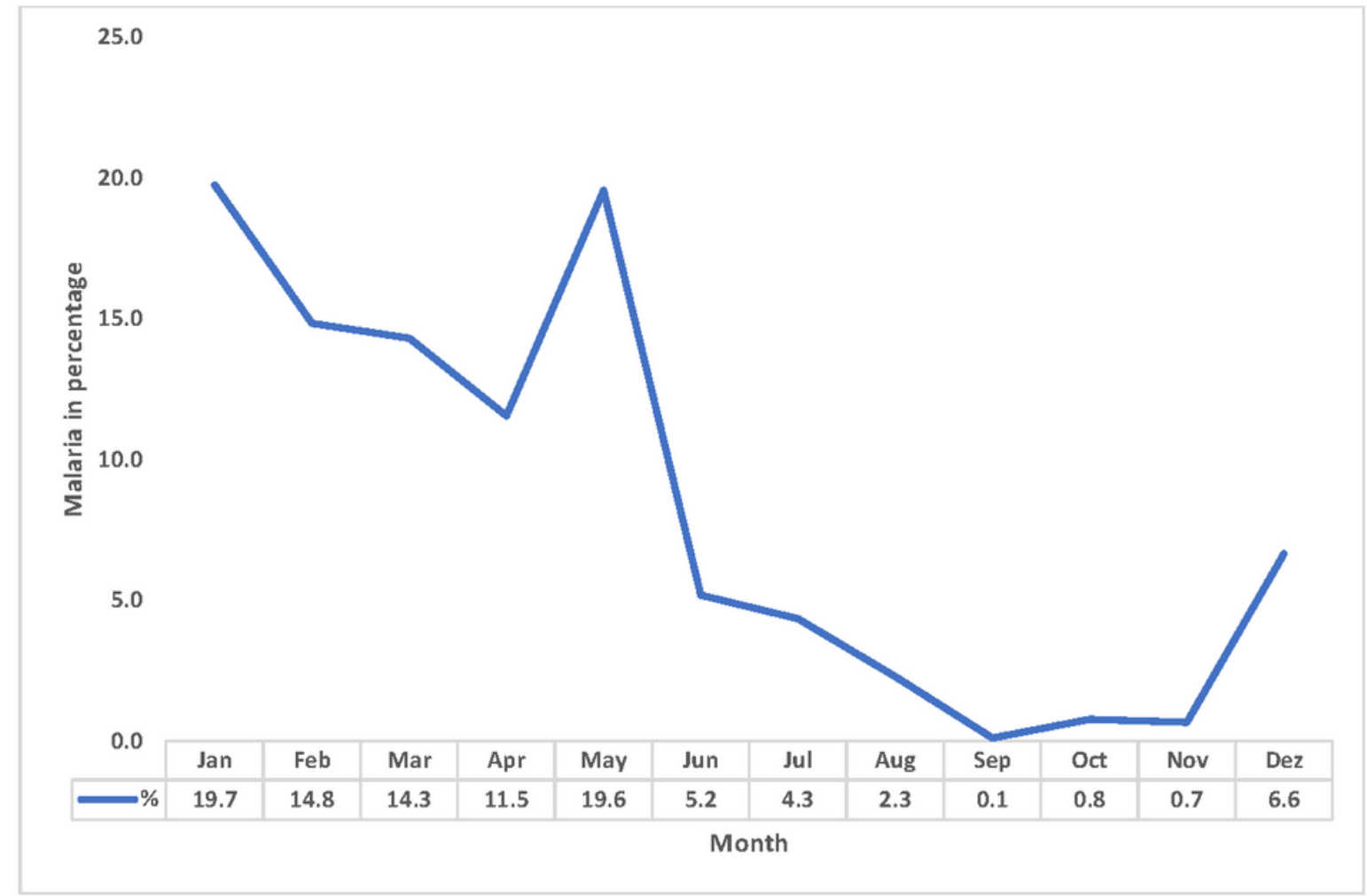

Figure 4

Pediatric malaria cases (\%) per month in Sussundenga Municipality, 2019. 

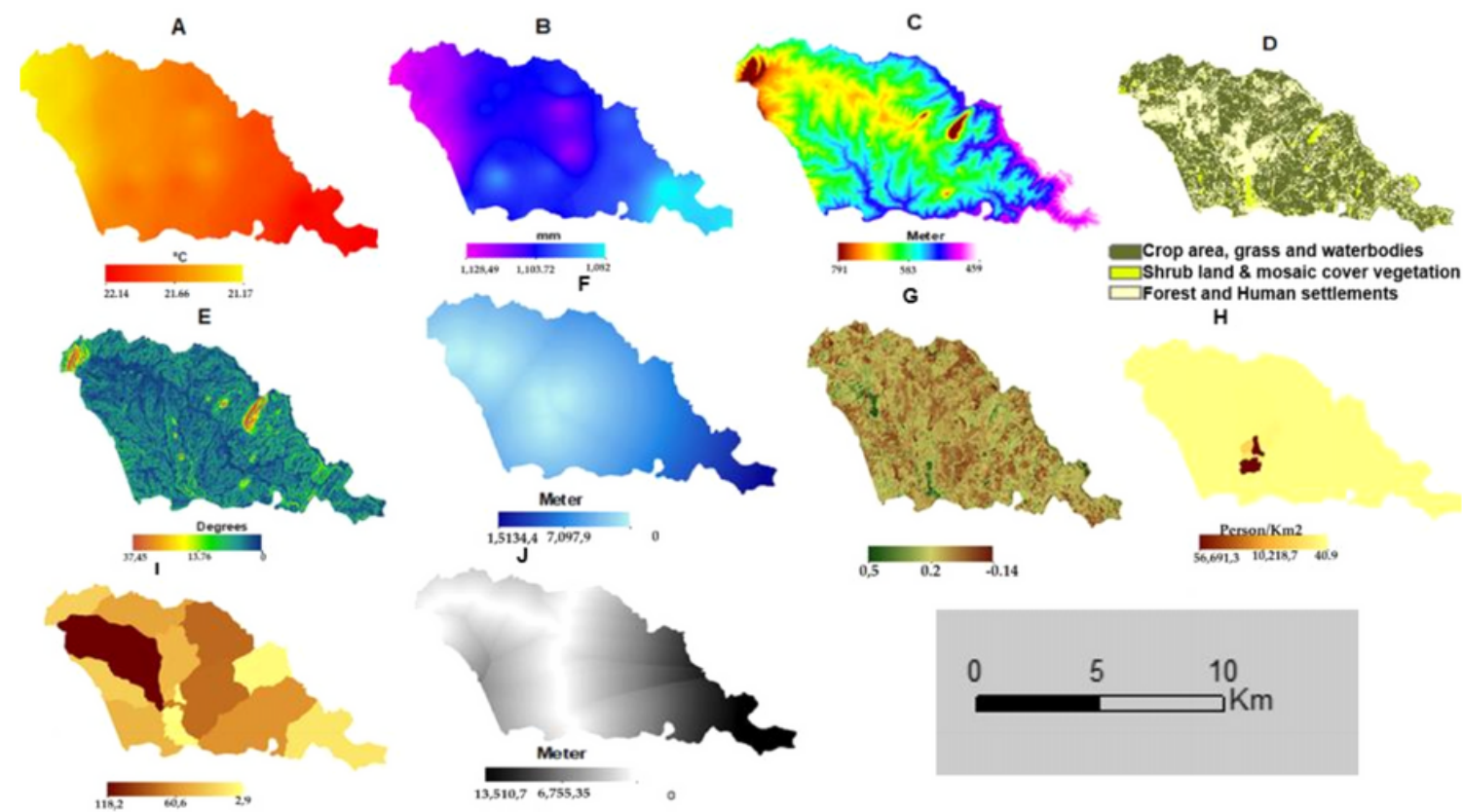

H
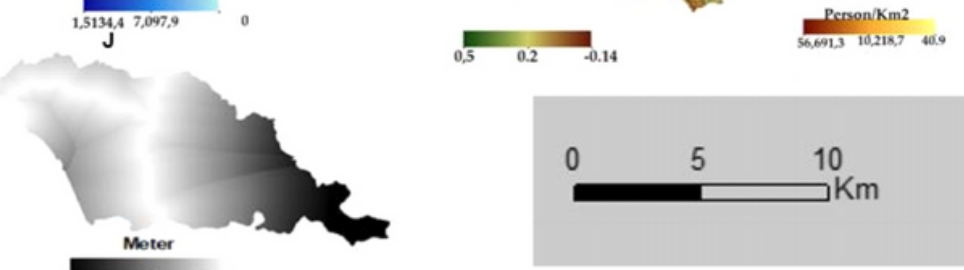

\section{Figure 5}

Unclassified malaria risk factors in Sussundenga Municipality. (A). Temperature. (B) Rainfall (C). Altitude. (D). LULC, (E) Slope (F). Distance to water bodies. (G) NDVI for Sussundenga Village (H). Pop. Density. (I). Malaria incidence. (J) Distance to roads. 

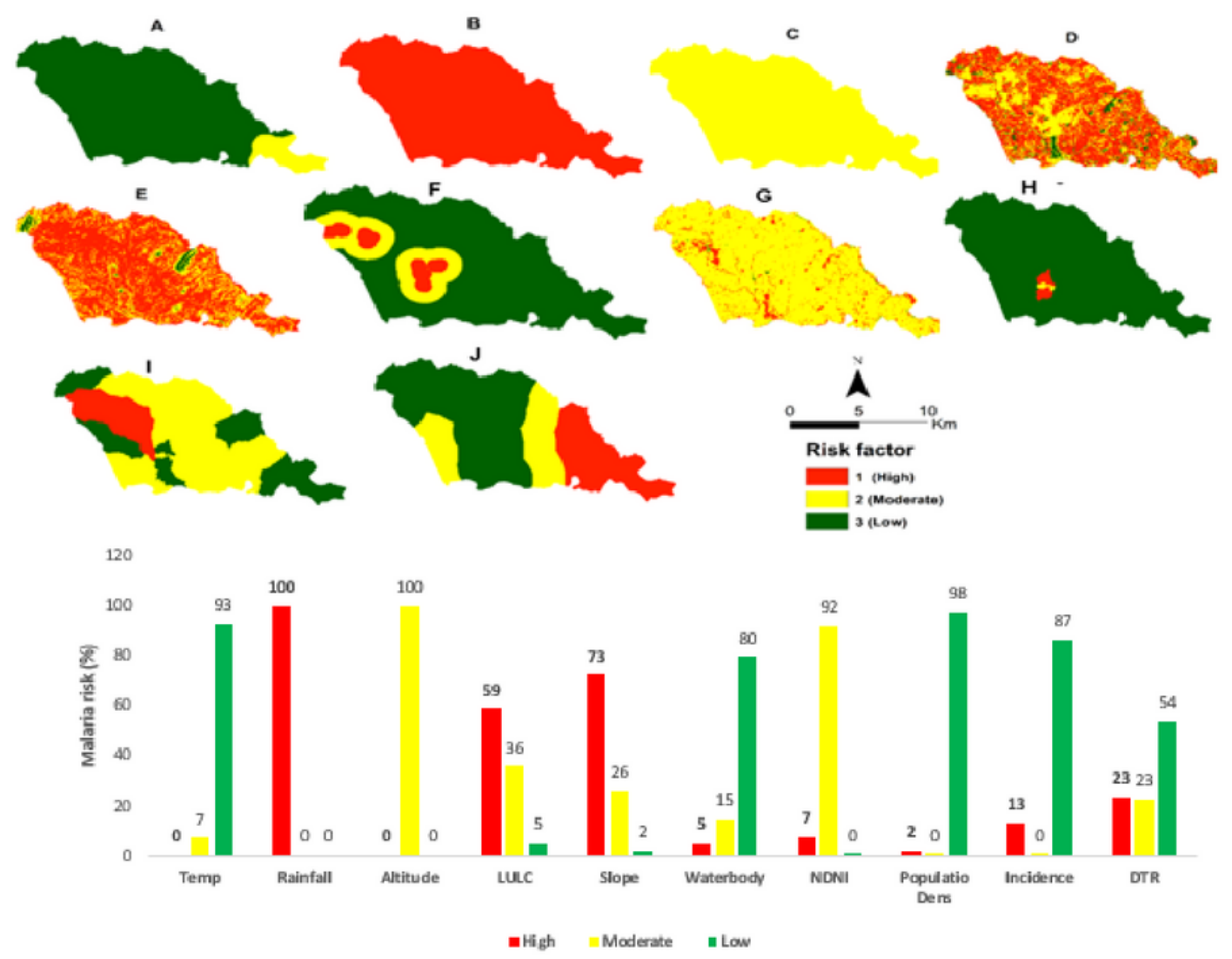

\section{Figure 6}

Reclassified malaria risk maps and malaria risk percentage. (A). Temperature. (B) Rainfall (C). Altitude. (D). LULC, (E) Slope, (F). Distance to water bodies. (G) NDVI for Sussundenga Village (H). Pop. Density. (I). Malaria Incidence. (J) Distance to roads.

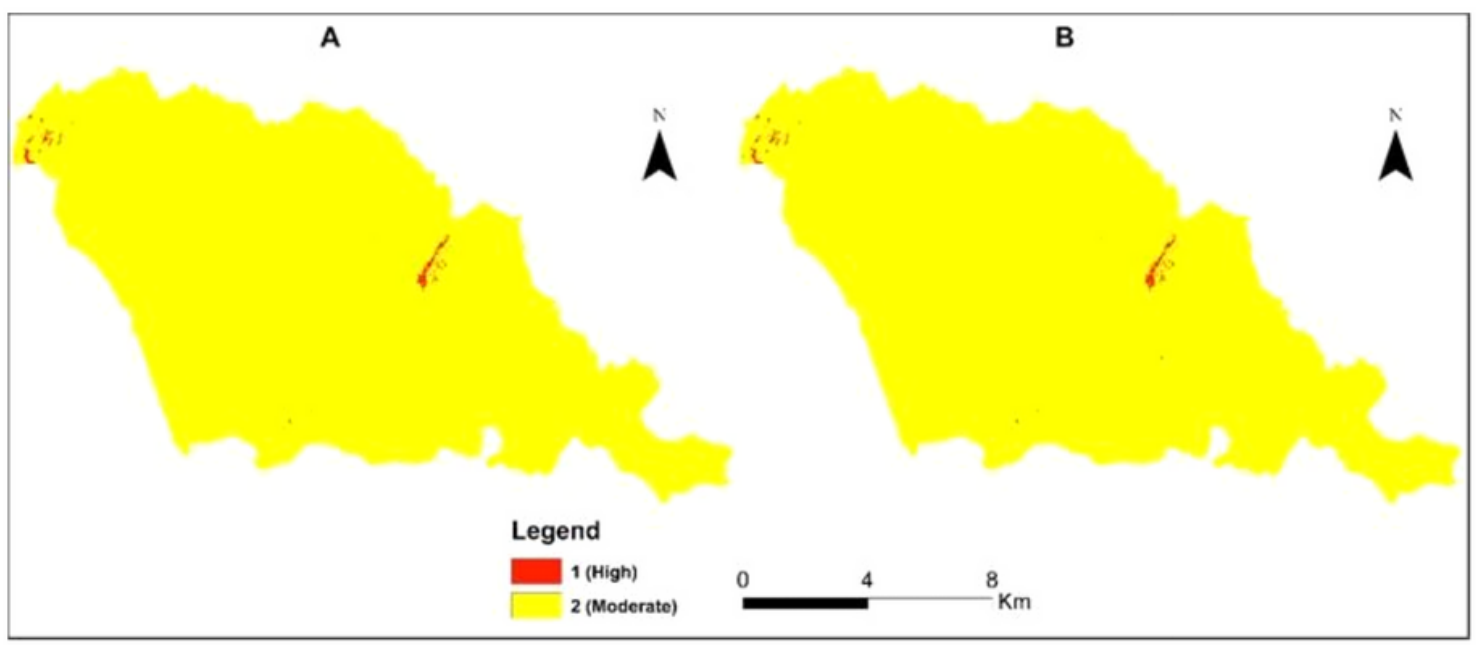


Malaria Risk Map for Sussundenga Municipality. A. Including incidence. B. Excluding

\section{Supplementary Files}

This is a list of supplementary files associated with this preprint. Click to download.

- Pediatricmalariadata.xlsx 